\title{
BMJ Open Nurses' educational needs when dealing with aggression from patients and their families: a mixed-methods study
}

To cite: Sato K, Kodama Y. Nurses' educational needs when dealing with aggression from patients and their families: a mixedmethods study. BMJ Open 2021;11:e041711. doi:10.1136/ bmjopen-2020-041711

- Prepublication history and additional material are published online only. To view please visit the journal online (http://dx.doi. org/10.1136/bmjopen-2020042305).

Received 16 June 2020 Revised 10 December 2020 Accepted 30 December 2020

D Check for updates

(c) Author(s) (or their employer(s)) 2021. Re-use permitted under CC BY-NC. No commercial re-use. See rights and permissions. Published by BMJ.

${ }^{1}$ Graduate School of Health Care Sciences, Tokyo Medical and Dental University, Bunkyo-ku, Tokyo, Japan

${ }^{2}$ School of Nursing and Rehabilitation Sciences, Showa University, Yokohama, Kanagawa, Japan

Correspondence to

Dr Kana Sato;

kn-sato@umin.ac.jp

\section{ABSTRACT}

Objectives To explore the type of education needed for nurses when dealing with aggression from patients and their families.

Design A two-phase sequential mixed-methods study. Setting This study was conducted in Japan, with phase I from March to November 2016 and phase II in November 2018.

Main outcome measures The challenges faced by nurses when dealing with incidents of aggression from the neutral perspective of neither nurse nor patient/family and perceptions of the educational contents developed in this study. Descriptive analyses were used to examine the data retrieved from both phases.

Participants Phase I entailed semistructured interviews among 11 neutral-party participants who observed aggressive incidents between nurses and patients/families. Phase II consisted of a web survey conducted among 102 nursing students and 308 nursing professionals.

Results Phase I resulted in the identification of the following five main educational components: understanding the mechanisms of anger and aggression, maintaining self-awareness, observant listening, managing the self-impression, and communicating based on specific disease characteristics. Each component was related to improved communication through self-awareness. The results of phase II indicated that participants positively perceived these educational contents as likely to be effective for dealing with aggression from patients/ families.

Conclusions This study clarified the type of education needed for nurses when dealing with aggression based on multiple viewpoints. Specifically, neutral-party interviews revealed that communication should be improved through self-awareness. A subsequent survey among nurses and nursing students showed that the identified educational contents were positively received.

\section{INTRODUCTION}

Research indicates that nurses may be at a higher risk of experiencing aggression from patients and their families than other healthcare professionals. ${ }^{1}$ Previous studies have also shown that such aggression is common in the hospital setting. ${ }^{23}$ For nursing professionals, these incidents may negatively impact overall health status ${ }^{4}$ in addition to posing several organisational problems, including
Strengths and limitations of this study

- Educational needs were explored from the perspectives of nurses/nursing students and from those of neutral-party observers.

- A mixed-methods approach allowed exploratory research developments, from the extraction of new elements through interviews to the evaluation of feasibility through a survey.

- The results may not reflect the characteristics of aggressive incidents that occur without neutral-party observation.

- The registered monitors of the marketing company recruited to conduct the web survey may not have assured sample representativeness.

an increased rate of on-the-job errors, ${ }^{5}$ reduced productivity, ${ }^{6}$ lower organisational commitment $^{7}$ and staff retention, ${ }^{8}{ }^{9}$ and increased healthcare costs. ${ }^{1}$ Aggression can also adversely affect patients, families and other involved parties. Timely and appropriate educational solutions are thus needed for prevention and management.

While several previous studies regarding educational interventions for nurses have shown that assessment, communication and breakaway skills may improve their attitudes, confidence and knowledge, incident rates have not been consistently reduced. ${ }^{10-13}$ Though these programmes were developed based on scientific research and the needs of actual nurses, their effectiveness thus appears to be limited.

The limitations to demand-based education for nurses could be explained by the characteristics of nurses' perceptions of aggressive events. Previous studies have shown that nurses' perceptions of patient aggression vary widely. While nurses have been known to downplay their victimisation experiences, believing they are simply a part of the job, ${ }^{14}$ they may sometimes overreact to patient aggression and thus neglect to provide adequate care. ${ }^{15}$ Furthermore, it has 
been implicated that it is difficult for nurses to have objectivity in aggressive events. It is well known that aggression faced by nurses is the result of the interaction of patients, healthcare providers and environmental factors, ${ }^{16}$ and it has also been shown that there is a lack of agreement in the perception of events between nurses and patients/ families. ${ }^{17-19}$ This means that those directly involved in the event may have difficulty being objective about the event.

As such, neutral-party assessments of incidents from persons other than nurses, patients or families may be useful for developing educational programmes aimed at helping nurses. Indeed, previous research suggests that persons observing incidents from a neutral position tend to conduct their evaluations from a panoramic perspective. ${ }^{20}$ At the same time, it is important that nurses, who are the recipients of any resulting educational interventions, agree with and accept the issues proposed by neutral parties. This study, therefore, adopted a mixedmethods sequential approach comprising two phases (ie, gaining neutral-party perspectives and surveying nurses' opinions on the results) to investigate the type of education needed to prevent and manage aggression directed at nursing professionals.

\section{Objectives}

This study aimed to explore the type of education nurses need when dealing with aggression from patients and their families. Specifically, this study (1) Explored neutralparty perspectives on the challenges faced by nurses when dealing with aggression and (2) Assessed how nurses and nursing students perceived these challenges as targets of educational contents.

\section{DESIGN}

A sequential mixed-methods design was employed. ${ }^{21}$ This consisted of two phases: a qualitative approach involving semistructured interviews among neutral parties who had observed aggressive incidents in phase I, and a quantitative approach involving a cross-sectional web survey among nurses and nursing students in phase II. An overview of the study design is shown in table 1 .

\section{METHODS}

\section{Phase I: semistructured interviews}

Participants

Participants comprised 11 neutral-party observers of aggressive incidents between nurses and patients/families. We purposefully chose participants based on their professional characteristics, comprising head nurses, risk managers, nursing faculty, and retired police officers employed in the mediating departments of hospitals. Here, we adopted a snowball sampling strategy to contact potential participants directly after our initial contacts informed us of their willingness to participate in this study.

\section{Data collection}

Data were collected over a 9-month period from March to November 2016. This was done through face-to-face semistructured interviews lasting approximately 45-90 min each, which were conducted by the first author. The interviewer was female and had clinical and academic experience of over 10 years. Participants were asked to provide overviews of cases in which patients or families had become aggressive with a nurse. Specifically, they were asked for their thoughts, feelings and actions regarding the nurse

Table 1 Overview of the study design

\begin{tabular}{|c|c|c|}
\hline & Phase I & Phase II \\
\hline Aim & $\begin{array}{l}\text { To identify the challenges for nurses when dealing } \\
\text { with patient and family aggression }\end{array}$ & $\begin{array}{l}\text { To assess how nurses and nursing students perceive phase I } \\
\text { results as educational contents }\end{array}$ \\
\hline Participants & $\begin{array}{l}\text { People who have experienced a neutral position } \\
\text { during an aggressive incident ( } n=11 \text {; head nurses, } \\
\text { risk managers, nursing faculty, retired police } \\
\text { officers employed in mediating departments of } \\
\text { hospitals) }\end{array}$ & Nurses $(n=308)$ and nursing students $(n=102)$ \\
\hline Recruitment & Purposive snowball sampling & Sampling from monitors of a marketing company \\
\hline $\begin{array}{l}\text { Data } \\
\text { collection }\end{array}$ & $\begin{array}{l}\text { Semistructured interviews were conducted } \\
\text { from March to November } 2016 \text {. The questions } \\
\text { concerned: } \\
\text { 1. Overview of the incident } \\
\text { 2. Perception of nurse's attitude } \\
\text { 3. Challenges and support needs for nurses in } \\
\text { dealing with aggressive incidents }\end{array}$ & $\begin{array}{l}\text { A cross-sectional web survey was conducted in November } \\
\text { 2018. The contents were: } \\
\text { 1. Perception of effectiveness of each item (5-point Likert } \\
\text { Scale) } \\
\text { 2. Favourable time for education on each item (choices and } \\
\text { free description) } \\
\text { 3. Favourable teaching method for each item (choices and } \\
\text { free description) }\end{array}$ \\
\hline $\begin{array}{l}\text { Data } \\
\text { analysis }\end{array}$ & $\begin{array}{l}\text { Coding and categorisation based on constant } \\
\text { comparative method }\end{array}$ & $\begin{array}{l}\text { Descriptive statistics for scale and choices, and grouping of } \\
\text { free descriptions }\end{array}$ \\
\hline
\end{tabular}


during those events, and to express their opinions about the challenges and support needs for nurses in general (online supplemental file 1). Interviews were conducted at the office of each participant or in a meeting room. Confidentiality and privacy were ensured for each participant during their interview. All interviews were digitally recorded and transcribed verbatim.

\section{Data analysis}

Data analysis was conducted through the qualitative descriptive method. ${ }^{22}{ }^{23}$ First, we carefully read the interview transcripts to gain a general sense of the described events. Second, the first author assigned a content-based code to each sentence that was further divided into semantic units and extracted codes that represented neutral assessments of aggressive incidents. Third, all extracted codes were examined and compared to identify areas of content overlap and similarity. Codes were then classified into 11 subcategories according to their similarities and differences. Subcategories were further sorted into five additional categories. We ensured that codes, subcategories and categories were reflective of nurses' challenges. Throughout the process, codes and categories were discussed among research peers specialising in qualitative analysis and individuals with expertise in nursing management.

\section{Phase II: cross-sectional web survey Participants}

Participants comprised 308 nurses and 102 undergraduate nursing students. We employed a large marketing company (Macromill) to recruit participants through a sampling process involving a wide range of variation. The inclusion criteria were as follows: registered nursing students or clinical nurses who were willing to participate.

\section{Data collection}

A cross-sectional web survey was conducted in November 2018. Survey items included sociodemographic characteristics, experiences with patient/family aggression, experiences with violence prevention education and items exploring participant views of education (online supplemental file 2). We included categories and subcategories that emerged during phase I as 10 educational contents. These items were developed by three researchers with backgrounds in nursing management and education to ensure that the wording of the subcategories obtained from phase I was appropriate. A 5-point Likert Scale ranging from 1 (completely effective) to 5 (completely ineffective) was used for the perception of effectiveness of each educational item. To explore a favourable time for teaching, participants chose from the following options: first half of undergraduate course, latter half of undergraduate course, 3 years or less after employment, 4-6years after employment, and 7years or more after employment. Next, we explored favourable teaching methods by asking participants to choose from the following options: self-learning using teaching materials, lecture, role-playing and discussion, e-learning, and others. These options were finalised after discussion among the researchers, referring to the methods used in existing educational programmes and the classification period of the clinical ladder in Japanese hospitals. ${ }^{24} \mathrm{We}$ also asked participants to provide open-ended responses including their opinions on favourable teaching times and methods.

\section{Data analysis}

Answers to the scale items and multiple-choice responses were overviewed using descriptive statistics, while openended responses were grouped and summarised.

\section{Reporting statement}

This study followed both the Strengthening the Reporting of Observational Studies in Epidemiology (STROBE) and Consolidated Criteria for Reporting Qualitative Research (COREQ) guidelines.

\section{Patient and public involvement statement}

There were no patients or instances of public participation in this study.

\section{Ethical considerations}

All participants were given written information about this study's rationale, purpose and procedures. Participants were also informed that they could withdraw from the study at any time and were assured of both the voluntary nature of their participation and confidentiality of all provided information. For phase I, written consent was obtained prior to participation. For phase II, survey respondents agreed to participate by clicking on an item indicating their cooperation prior to completing the questionnaire. Submissions were thus taken as consent to participate.

\section{Rigour}

For phase I, trustworthiness was ensured through purposive sampling targeted at diversity, continuous data comparison, discussion among the researchers, triangulation using field notes, and an auditing trail of the coding and categorisation processes.

For phase II, web questionnaire contents were repeatedly discussed to enhance face validity. Additionally, registered monitors of the marketing and research company were selected as participants in order to maximise variation while minimising enforcement and bias in the sample, which may have occurred if participants were recruited through their respective organisations.

\section{RESULTS}

Phase I-interview findings: neutral-party perspectives on nursing challenges

There were 11 participants in this phase, including 4 head hospital nurses (representing outpatient, psychiatric, emergency and home care departments), 1 hospital risk manager, 2 nursing faculty members specialising in 
nursing management, 3 retired police officers employed in the mediating departments of hospitals and 1 office worker from a hospital security company. Participants ranged in age from their $40 \mathrm{~s}$ to $70 \mathrm{~s}$, and 7 of the 11 participants were female. The participants recalled a total of 15 incidents: 5 incidents within 6 months, 7 incidents within a year, and 3 incidents within 2 years. All the events were

Neutral-party descriptions resulted in five categories of challenges presented to nurses when dealing with aggression from patients and their families. These included (1) Understanding the mechanisms of anger and aggression, (2) Maintaining self-awareness, (3) Observant listening, (4) Managing the self-impression, and (5) Communicating based on specific disease characteristics. impressive and memorable to the participants.
All participants believed that aggressive behaviour by patients and their families resulted from or was exacerbated by nurses' behavioural stimuli not characterised by the above-mentioned categories. Table 2 shows the categories, subcategories and examples of raw data regarding the challenges presented to nurses when dealing with patient/family aggression.

\section{Phase II-web survey findings: viewpoints from nurses and nursing students regarding the presentation of phase I challenges as educational contents}

Participants' sociodemographic characteristics are shown in table 3. Most nurses were female, in non-managerial positions, worked at hospitals and had experience with patient/family aggression, while most nursing students
Table 2 Challenges faced by nurses when dealing with patient/family aggression as perceived by neutral-party observers

\begin{tabular}{lll}
\hline Categories & Subcategories & Explanation of categories and subcategories \\
$\begin{array}{l}\text { Understanding the } \\
\text { mechanisms of anger } \\
\text { and aggression }\end{array}$ & $\begin{array}{l}\text { Understanding the } \\
\text { causes of anger }\end{array}$ & $\begin{array}{l}\text { One element that formed initial reactions among nurses } \\
\text { when attacked was understanding the causes of anger } \\
\text { and processes of aggression. With these understandings, } \\
\text { nurses could think over the hidden background factors } \\
\text { and structures of the aggression that had emerged as the } \\
\text { tip of the iceberg'. Participants thought this would help } \\
\text { nurses recognise the situation as an observer rather than }\end{array}$ \\
& $\begin{array}{ll}\text { Understanding the } \\
\text { process of aggression }\end{array}$
\end{tabular}
Examples of raw data

It may seem like daily routine to us, but it is an extraordinary event for a patient's family, which makes them feel confused and exhausted with anxiety and regret. If we don't keep that in mind and take care of patients' families, we hurt them and make them angry. (head nurse)

If you don't think that the frustration was accumulating while you were around, you will think 'I was blamed' and you will not be able to understand the other person. (retired police officer)
Maintaining selfawareness
Understanding one's Participants identified nurses' self-awareness as another vulnerability to attacks component of the initial response to the attack. Selfawareness here refers to the act of analysing one's personality traits through one's emotions, thoughts

Facing one's weaknesses

$\begin{array}{ll}\text { Observant listening } & \begin{array}{l}\text { Observing and } \\ \text { analysing while } \\ \text { listening }\end{array} \\ & \text { Maintaining a bird's- } \\ \text { eye view while } & \text { listening }\end{array}$

Managing the selfimpression and actions. While an emotional reaction is inevitable, introspection on it and acceptance of one's weaknesses may optimise emotion-related behaviour. Participants recognised the importance of nurses' self-awareness frozen when attacked; the nurse was stimulated and out of control; and the nurse was resistant to introspection. situation while listening.

When being attacked verbally, nurses tended to focus too much on what was said, losing perspective of the larger picture and ultimately making the situation worse. Participants thought that it was important to observe the patient and take a step back in order to explore the patient's true needs and control the way the aggressive event was recognised by the patient and others.

Sending intentional Many participants referred to the need for nurses to pay non-verbal messages more attention to their own behaviour. They felt that competencies through the following cases: the nurse was the patient's claim and to assess his/her mental state and have understood that he was naturally irritable, that he

The male nurse did not expect to be attacked by the patient. He was first shocked and frozen, and then lost control of himself and his surroundings because of his fear and anger. (retired police officer)

Some people will not accept any attempt to make them reflect. It seems that such an attitude is related to the person's growth history. In such a situation, it is difficult for them to improve unless they themselves try to do something about it. (head nurse) was angry and sad, or that he was scared. (head nurse) Depending on how we react, we can make the patient's aggressive event look like something big or something a little emotional. I think it is very important for us to think about how people around us will see the scene of verbal aggression from patients. In other words, it could be taking a step back and looking at the big picture. (risk manager) nurses' way of speaking and expressions could stimulate patients and their families, and sometimes undermined the effectiveness of dialogue. Some participants thought that nurses were often unaware of or underestimated the impact of their own behaviour, and spoke of the need for Paying close attention improvements in this regard. to one's every movement

\begin{tabular}{|c|c|c|}
\hline $\begin{array}{l}\text { Communicating } \\
\text { based on } \\
\text { specific disease } \\
\text { characteristics }\end{array}$ & $\begin{array}{l}\text { Using skills } \\
\text { depending on specific } \\
\text { diseases } \\
\text { Parrying aggression } \\
\text { Showing a resolute } \\
\text { attitude towards } \\
\text { manipulators }\end{array}$ & $\begin{array}{l}\text { The participants were aware that nurses should learn } \\
\text { disease-specific communication skills. In particular, in } \\
\text { the case of manipulative people, the participants thought } \\
\text { that showing empathy through general communication } \\
\text { could worsen the situation. Participants said that nurses } \\
\text { who believed they could understand patients by dialogue } \\
\text { were vulnerable to manipulators. Participants recognised } \\
\text { the importance of acquiring knowledge about the nature } \\
\text { of the disease, identifying manipulative persons at an } \\
\text { early stage, and taking a resolute stance. }\end{array}$ \\
\hline
\end{tabular}

In terms of gaze, it may be difficult to look into a person's eyes seriously without appearing to be glaring. I think your gaze is a good way to show that you're not hostile, that you're facing things sincerely, and that you're resolute in dealing with unacceptable claims. (head nurse)

I know it is unintentional, but she's usually careless about every move...the way she closes the door is rude, and she interrupts the patient. (head nurse)

A lot (the manipulating behaviour of the personality disorders) is already known, and if we don't make use of that knowledge, we will suffer unnecessary harm. (nursing faculty)

She became involved when she approached the patient in an attempt to reach his position. In that case, we have to get ourselves ready and protect ourselves as soon as possible. (head nurse) 
Table 3 Sociodemographic data of online survey participants (phase II), n=410

\begin{tabular}{|c|c|c|c|c|c|c|c|c|}
\hline & \multicolumn{4}{|c|}{ Nurses $(n=308)$} & \multicolumn{4}{|c|}{ Nursing students $(n=102)$} \\
\hline & Mean & (SD) & $n$ & $(\%)$ & Mean & (SD) & $n$ & $(\%)$ \\
\hline \multicolumn{9}{|l|}{ Gender } \\
\hline Age & 36.4 & $(9.18)$ & & & 20.1 & $(1.61)$ & & \\
\hline Work experience (years) & 12.1 & (8.03) & & & & $\mathrm{V} / \mathrm{A} \dagger$ & & \\
\hline \multicolumn{9}{|l|}{ Work setting } \\
\hline Hospital & & & 235 & (76.3) & & & \multicolumn{2}{|r|}{ N/A† } \\
\hline Clinic, home nursing & & & 34 & $(11.0)$ & & & & \\
\hline Nursing care facilities & & & 29 & $(9.4)$ & & & & \\
\hline Second & & & & & & & 25 & $(24.5)$ \\
\hline Third & & & & & & & 18 & $(17.6)$ \\
\hline Fourth & & & & & & & 20 & (19.6) \\
\hline \multicolumn{9}{|c|}{ Experience with patient care in undergraduate clinical training } \\
\hline Yes & \multicolumn{4}{|c|}{ N/A† } & & & 84 & $(82.4)$ \\
\hline \multicolumn{9}{|c|}{ Experience of patient/family aggression (multiple answers) } \\
\hline Physically inflicted aggression & & & 225 & $(73.1)$ & & & 7 & $(8.3)^{*}$ \\
\hline Mentally inflicted aggression & & & 230 & $(74.7)$ & & & 7 & $(8.3)^{*}$ \\
\hline \multicolumn{9}{|l|}{ Experience with violence prevention education } \\
\hline Others & & & 1 & $(0.8)^{\star}$ & & & 2 & $(5.7)^{\star}$ \\
\hline
\end{tabular}

*Percentage was calculated using the number who answered 'Yes' in the previous question as the denominator. $+\mathrm{N} / \mathrm{A}$ indicates that the item was not included in the questionnaire.

were female and had not experienced aggression during patient care.

\section{Effectiveness of each item}

The viewpoints of nurses and nursing students about the effectiveness of the educational contents are shown in figure 1 . As shown, more than $70 \%$ perceived all such contents as completely or mostly effective.

\section{Favourable times to learn each item}

Figure 2 shows how participants perceived favourable times for learning the educational contents, while table 4 shows a summary of their open-ended responses to this element. The top two selections for all educational contents were 'latter half of undergraduate course' and '3years or less after employment' in nurses, while first and latter half of undergraduate course were regarded as favourable in nursing students. The open-ended responses revealed that participants mainly focused on the importance of earliness, readiness and phased education.

Favourable teaching methods for each item

Figure 3 shows the responses to the favourable teaching methods items, while table 4 shows a summary of openended responses to this element. As shown, the top two responses were 'lecture' and 'practice style' (ie, roleplaying and discussion). Generally, the lecture style was preferred for understanding anger, while the practice style was preferred for self-analysis and skills acquisition. Open-ended responses revealed that participants mainly focused on the importance of interaction, combination and accessibility (table 4). Notably, some participants 
Nurses $(\mathrm{N}=308)$

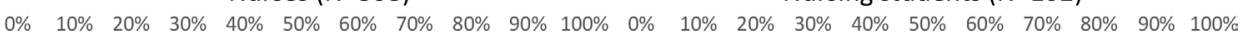

1. Understanding the causes of anger

2. Understanding the process of aggression

3. Understanding one's vulnerability to attacks

4. Understanding and facing own weaknesses

5. Observing and analysing while listening

6. Maintaining a bird's-eye view while listening

7. Managing self-impression

8. Using skills depending on specific diseases

9. Parrying aggression

10. Showing resolute attitude

\begin{tabular}{|c|c|c|}
\hline 101 & 168 & 2982 \\
\hline 122 & 141 & $37 \quad 71$ \\
\hline 109 & 127 & $58 \quad 12$ \\
\hline 99 & 144 & 56 g) \\
\hline 118. & 130 & 58 \\
\hline 104 & 140 & 59 \\
\hline 104 & 130 & 63 \\
\hline 119 & 127 & $53 \quad 72$ \\
\hline 138 & 128 & 35 7p \\
\hline 95 & 21 & 143 \\
\hline
\end{tabular}

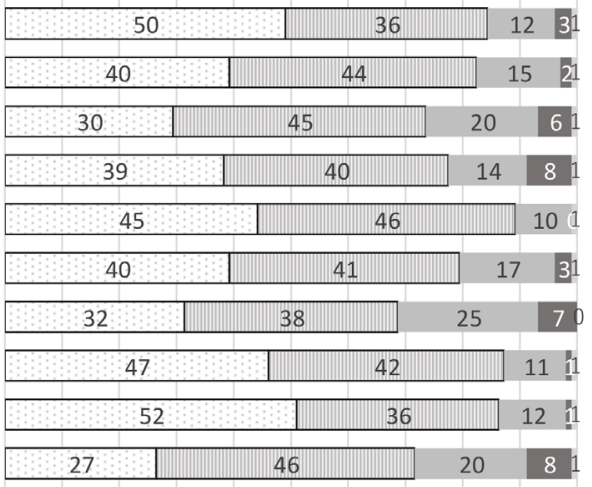

$\square$ Completely $\square$ Mostly $\square$ Undecided $\square$ Mostly not $\square$ Completely not

Figure 1 Perceptions of effectiveness of educational contents among nurses and nursing students.

viewed interaction positively, while others did not and the latter group had concerns about sharing their self-analyses.

\section{DISCUSSION}

This mixed-methods study solicited neutral-party perspectives to clarify the challenges faced by nurses when dealing with aggression from patients and their families and assessed how the resulting educational contents were perceived by possible learners, namely, nurses and nursing students. The results showed that most respondents evaluated the educational contents positively. However, individual differences were found with regard to the preferred teaching times and methods.

Notably, this study identified educational contents for areas that required strengthening. This was different from most previous studies, which examined the effects of educational interventions aimed at violence prevention by focusing on behaviour management. ${ }^{25}$ Neutral parties indicated that interventions should prioritise enhanced communication. Aggression management procedures have traditionally focused on coercive approaches, such as those involving the use of tranquillising medications, restraints and seclusion. However, more recent views emphasise preventive methods that entail less restrictive interventions ${ }^{26}$ and the importance of ensuring that healthcare providers develop their communication skills. ${ }^{27} 28$ This study's results support this changing trend in the area of aggression management. In particular, we found that self-awareness was highly important. This is consistent with current trends in aggressive behaviour research, which indicate the importance of exploring nurses' personal characteristics. ${ }^{29}{ }^{30}$ However, previous studies on communication have not emphasised this issue, ${ }^{31} 32$ including the concept of de-escalation. Our findings could be applied to future communication education.

Of further significance, this study also showed that potential learners had different preferences with regard to the timing and methods of education. In particular, participant preferences for the educational method for self-awareness were divided between those who preferred the lecture style and those who preferred the practice style. The free description results indicated that these differences may be owing to how participants perceived their interactions with others in practice. This could be explained by the fact that it is inherently
1. Understanding the causes of anger

2. Understanding the process of aggression

3. Understanding one's vulnerability to attacks

4. Understanding and facing own weaknesses

5. Observing and analysing while listening

6. Maintaining a bird's-eye view while listening

7. Managing self-impression

8. Using skills depending on specific diseases

9. Parrying aggression

10. Showing resolute attitude
Nurses $(\mathrm{N}=308)$

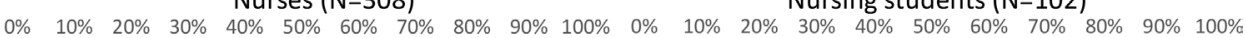

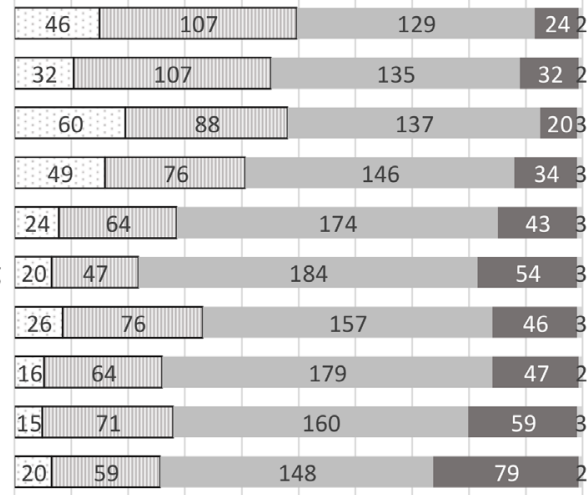

$\square$ First half of undergraduate course प 4 to 6 years after employment

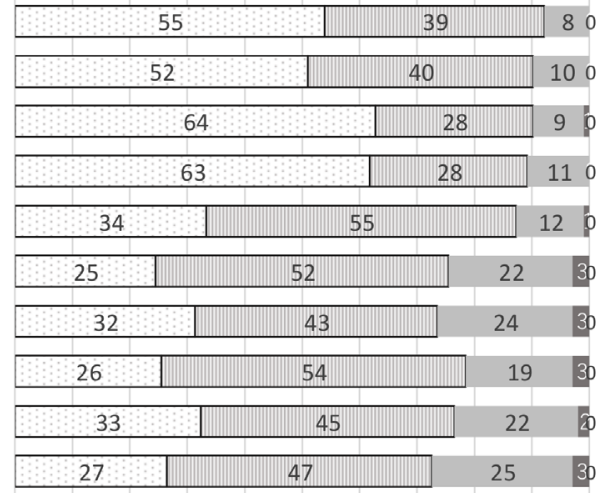

$\square$ Latter half of undergraduate course $\square$ - 3 years or less after employment 7 years or more after employment

Figure 2 Perceptions of favourable time for educational contents among nurses and nursing students. 
Table 4 Participants' rationale for choosing teaching strategies for violence prevention elucidated from free descriptions

Favourable time for education

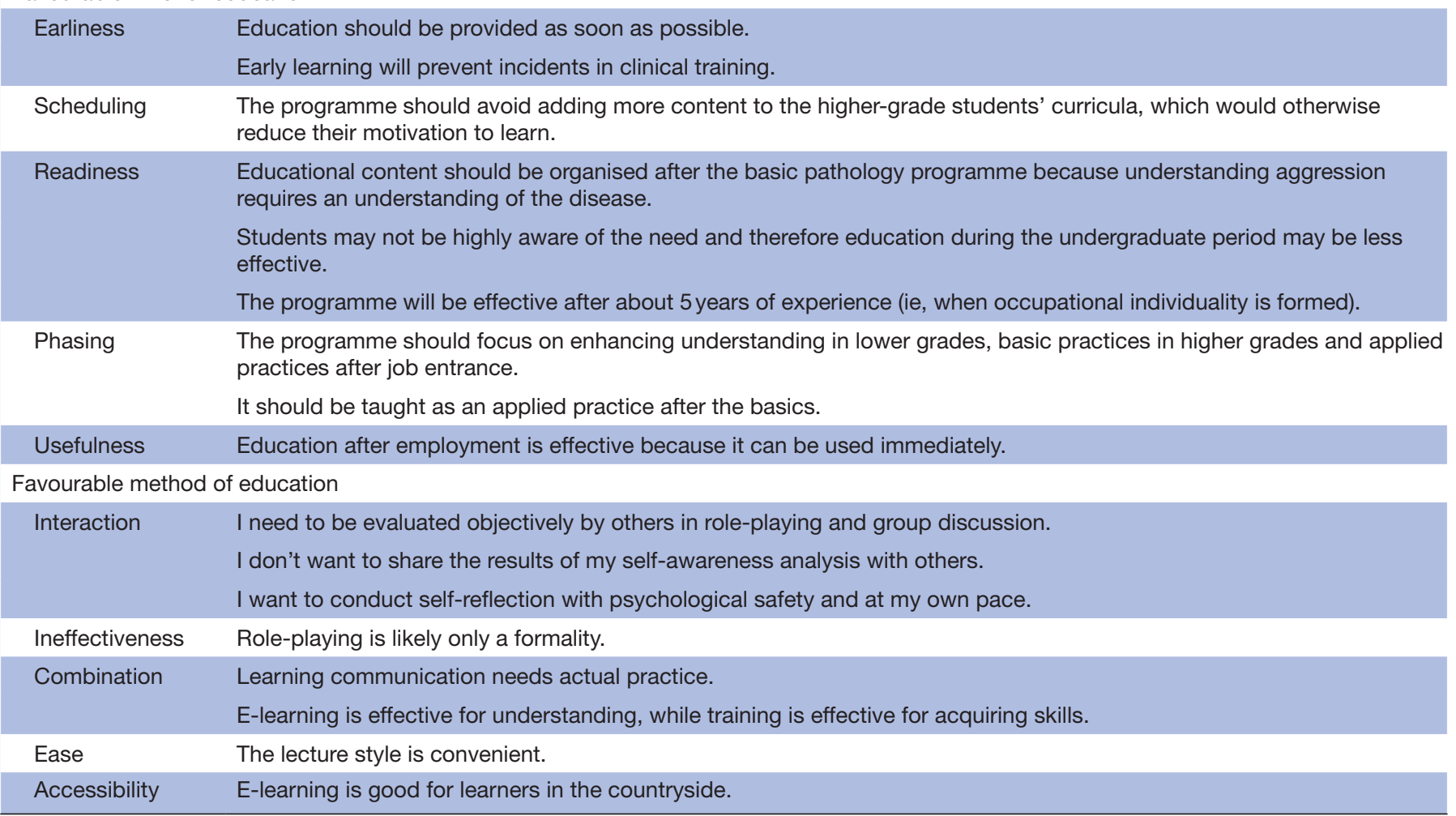

stressful to face violence, which may varyingly influence individual readiness and vulnerability. Further, nurses with histories of toxic relationships are known to be vulnerable to workplace violence. ${ }^{33}$ As these are highly personal aspects, participants may have been uncomfortable making these elements known to others. While the practice style is highly effective with regard to general skill acquisition especially in group training, it is still necessary to ensure that participants are given the freedom to refuse or suspend participation. In addition, educational interventions may result in flashbacks regardless of the method. This means that educators should always consider the need to keep pace with learners while maintaining confidentiality. It should also be considered that the majority of nursing students believed that early educational intervention was favourable.

This study also had several limitations. First, educational contents were extracted based on specific cases in which neutral parties were present. As such, these contents may not reflect cases in which incidents are unrecognised, unreported or that required police intervention. Second, we were not able to ensure participant representativeness during the web survey. Although the gender and affiliation ratios were similar to national ratios, the characteristics of the registered monitors from the marketing company were unknown. Especially, the number of nursing students included was low. This was because of the small number of nursing students registered
Nurses $(\mathrm{N}=308)$

\begin{tabular}{|c|c|c|c|c|c|c|c|}
\hline 25 & & & & 213 & & & \\
\hline
\end{tabular}

$\square$ Self-learning using teaching materials $\square$ Lecture



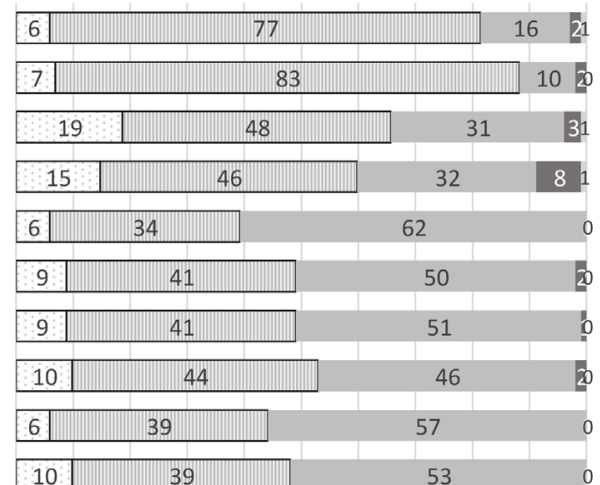

- Role-playing and Discussion $\quad$ E-learning $\quad$ Others

Figure 3 Perceptions of favourable method of educational contents among nurses and nursing students. 
with the marketing company (although the company is one of the largest in the country). Although it is expected that the use of survey monitors resulted in less of a bias in terms of the demographics of the target population than if recruitment had been conducted on an organisational basis, the results should be interpreted with caution. Third, the two groups of participants-nurses and nursing studentswere of different social and professional status and have very different levels of exposure to patient/family aggression, and this needs to be taken into account when interpreting the results. Finally, many participants had not received formal education in violence prevention, meaning that their evaluations of programme effectiveness entailed speculation.

Nevertheless, this is the first study to clarify the education needed for nurses based on multiple viewpoints. We were, therefore, able to present educational contents that could not be extracted solely through survey data collected from nurses. At the same time, we were able to propose the feasibility of implementing such contents by asking nurses and nursing students to evaluate their acceptability. Future studies are needed to verify effectiveness by implementing these contents through an undergraduate course or inservice programme in the professional setting. This will enable various comparisons with existing educational programmes using clinical indicators such as the violence incidence rate, health status of nurses, quality of nursing care and medical expenses.

\section{CONCLUSION}

The findings of this study showed that communication and self-awareness were important areas that required strengthening based on neutral-party evaluations. Further, nurses and nursing students positively evaluated the perceived effectiveness of the identified educational contents.

Correction notice This article has been corrected since it first published. The provenance and peer review statement has been included.

Acknowledgements The authors thank all the study participants who shared their time and experiences with them. The authors also thank Dr Keiko Okuma and Ms Mika Kimura for their support.

Contributors SK designed the study and collected the data. SK and KY analysed the data, and drafted and revised the manuscript.

Funding This work was supported by JSPS (Japan Society for the Promotion of Science) KAKENHI Grant Numbers 15H06527 and 17K17404.

Competing interests None declared.

Patient consent for publication Not required.

Ethics approval This study was approved by the Institutional Review Board of Miyagi University (1487) and Tokyo Medical and Dental University (M2018-163).

Provenance and peer review Not commissioned; externally peer reviewed.

Data availability statement No additional data are available.

Supplemental material This content has been supplied by the author(s). It has not been vetted by BMJ Publishing Group Limited (BMJ) and may not have been peer-reviewed. Any opinions or recommendations discussed are solely those of the author(s) and are not endorsed by BMJ. BMJ disclaims all liability and responsibility arising from any reliance placed on the content. Where the content includes any translated material, BMJ does not warrant the accuracy and reliability of the translations (including but not limited to local regulations, clinical guidelines, terminology, drug names and drug dosages), and is not responsible for any error and/or omissions arising from translation and adaptation or otherwise.
Open access This is an open access article distributed in accordance with the Creative Commons Attribution Non Commercial (CC BY-NC 4.0) license, which permits others to distribute, remix, adapt, build upon this work non-commercially, and license their derivative works on different terms, provided the original work is properly cited, appropriate credit is given, any changes made indicated, and the use is non-commercial. See: http://creativecommons.org/licenses/by-nc/4.0/.

ORCID iD

Kana Sato http://orcid.org/0000-0002-2106-579X

\section{REFERENCES}

1 International Labour Office, International Council of Nurses, World Health Organization and Public Services. International framework guidelines for addressing workplace violence in the health sector. Geneva: International Labour Office, 2002.

2 Shi L, Zhang D, Zhou C, et al. A cross-sectional study on the prevalence and associated risk factors for workplace violence against Chinese nurses. BMJ Open 2017;7:e013105.

3 Jackson D, Hutchinson M, Luck L, et al. Mosaic of verbal abuse experienced by nurses in their everyday work. J Adv Nurs 2013;69:2066-75.

4 Zhang SE, Liu W, Wang J, et al. Impact of workplace violence and compassionate behaviour in hospitals on stress, sleep quality and subjective health status among Chinese nurses: a cross-sectional survey. BMJ Open 2018;8:e019373.

5 Farrell GA, Bobrowski C, Bobrowski P. Scoping workplace aggression in nursing: findings from an Australian study. J Adv Nurs 2006;55:778-87.

6 Gates DM, Gillespie GL, Succop P. Violence against nurses and its impact on stress and productivity. Nurs Econ 2011;29:59-66.

7 Camerino D, Estryn-Behar M, Conway PM, et al. Work-Related factors and violence among nursing staff in the European next study: a longitudinal cohort study. Int J Nurs Stud 2008;45:35-50.

8 Liu W, Zhao S, Shi L, et al. Workplace violence, job satisfaction, burnout, perceived organisational support and their effects on turnover intention among Chinese nurses in tertiary hospitals: a cross-sectional study. BMJ Open 2018;8:e019525.

9 Zhan Y, Kim SK, Zhou L, et al. Patient violence and health professionals' occupational outcomes in China: a time-lagged survey study. Int J Nurs Stud 2019;94:120-30.

10 Lakatos BE, Mitchell MT, Askari R, et al. An interdisciplinary clinical approach for workplace violence prevention and injury reduction in the General Hospital setting: S.A.F.E. response. J Am Psychiatr Nurses Assoc 2019;25:280-8.

11 Tölli S, Partanen P, Kontio R, et al. A quantitative systematic review of the effects of training interventions on enhancing the competence of nursing staff in managing challenging patient behaviour. J Adv Nurs 2017;73:2817-31.

12 Heckemann B, Zeller A, Hahn S, et al. The effect of aggression management training programmes for nursing staff and students working in an acute hospital setting. A narrative review of current literature. Nurse Educ Today 2015;35:212-9.

13 Spelten E, Thomas B, O'Meara PF. Organisational interventions for preventing and minimising aggression directed towards healthcare workers by patients and patient advocates. Issue 4. Art. No.: CD012662. Cochrane Database of Systematic Reviews, 2020.

14 Ferns T, Chojnacka I. Reporting incidents of violence and aggression towards NHS staff. Nurs Stand 2005;19:51-6.

15 Sato K, Yumoto Y, Fukahori H. How nurse managers in Japanese hospital wards manage patient violence toward their staff. $J$ Nurs Manag 2016;24:164-73.

16 Gillespie GL, Gates DM, Miller M, et al. Workplace violence in healthcare settings: risk factors and protective strategies. Rehabil Nurs 2010;35:177-84.

17 Vandecasteele T, Debyser B, Van Hecke A, et al. Patients' perceptions of transgressive behaviour in care relationships with nurses: a qualitative study. J Adv Nurs 2015;71:2822-33.

18 Babaei N, Rahmani A, Avazeh M, et al. Determine and compare the viewpoints of nurses, patients and their relatives to workplace violence against nurses. J Nurs Manag 2018;26:563-70.

19 Lamanna D, Ninkovic D, Vijayaratnam V, et al. Aggression in psychiatric hospitalizations: a qualitative study of patient and provider perspectives. J Ment Health 2016;25:536-42.

20 Yagil D, Dayan H. Justification of aggression against nurses: the effect of aggressor distress and nurse communication quality. $J A d v$ Nurs 2020;76:611-20.

21 Creswell JW. Designing and conducting mixed methods research. $3^{\text {rd }}$ edition. SAGE Publications Inc, 2017. 
22 Miles MB, Huberman AM, Saldana J. Qualitative data analysis: a methods Sourcebook. 3rd edition. SAGE Publications Inc, 2013.

23 Saldana J. The coding manual for qualitative researchers. $3^{\text {rd }}$ Edition. SAGE Publications Ltd, 2015.

24 Japanese Nursing Association. Survey on training for quality improvement of nursing in small and medium-sized hospitals.(in Japanese). Available: https://www.nurse.or.jp/nursing/education/ jissen/document/index.html

25 de la Fuente M, Schoenfisch A, Wadsworth B, et al. Impact of behavior management training on nurses' confidence in managing patient aggression. J Nurs Adm 2019;49:73-8.

26 Beech B, Leather P. Workplace violence in the health care sector: a review of staff training and integration of training evaluation models. Aggress Violent Behav 2006;11:27-43.

27 Duxbury J. Testing a new tool: the management of aggression and violence attitude scale (MAVAS). Nurse Res 2003;10:39-52.

28 Calabro K, Mackey TA, Williams S. Evaluation of training designed to prevent and manage patient violence. Issues Ment Health Nurs 2002;23:3-15.
29 Krull W, Gusenius TM, Germain D, et al. Staff perception of interprofessional simulation for verbal de-escalation and restraint application to mitigate violent patient behaviors in the emergency department. J Emerg Nurs 2019;45:24-30.

30 Ferrara KL, Davis-Ajami ML, Warren Jl, et al. De-Escalation training to medical-surgical nurses in the acute care setting. Issues Ment Health Nurs 2017;38:742-9.

31 de Looff P, Nijman H, Didden R, et al. Burnout symptoms in forensic psychiatric nurses and their associations with personality, emotional intelligence and client aggression: a cross-sectional study. $J$ Psychiatr Ment Health Nurs 2018;25:506-16.

32 Molero Jurado MDM, Pérez-Fuentes MDC, Barragán Martín $A B$, et al. Personality and the Moderating effect of mood on a verbal aggressiveness risk factor from work activities. J Clin Med 2018;7:525

33 Anderson C. Workplace violence: are some nurses more vulnerable? Issues Ment Health Nurs 2002;23:351-66. 